\title{
ĐÁNH GIÁ MộT Số CHİ TIÊU VI SINH VẬT TRONG THỨC ĂN ĐƯờNG PHỐ Ở PHƯỜNG AN Cựu, THÀNH PHỐ HUẾ
}

\author{
Phạm Thị Ngọc Lan', Ngô Thị Bảo Châu', Trần Thị Hoàng Oanh² \\ ${ }^{1}$ Truoòng Đại hoc Khoa học, Đại học Huế \\ ${ }^{2}$ Trung tâm công nghệ Sinh học Đà Nã̃ng
}

(Ngày đến tòa soạn: 30/6/2019; Ngày sửa bài sau phản biện: 12/9/2019;

Ngày chấp nhận đăng: 20/9/2019)

\section{Tóm tắt}

Đã khảo sát tình hình vệ sinh an toàn thực phẩm của 116 mẫu cơm hến và bún hến ở phường An Cựu, thành phố Huế. Tỷ lệ mẫu đạt về các chỉ tiêu tổng số vi sinh vật hiếu khí, tổng nấm men, nấm mốc của cơm hến khô lần lượt là $0,9 \%$ và $5,1 \%$, đối với cơm hến nước, lần lượt là $1,7 \%$ và $4,3 \%$; ở bún hến, lần lượt là $2,6 \%$ và $3,4 \%$. Trong 116 mẫu khảo sát đều không có mẫu đạt yêu cầu của Bộ Y tế về chỉ tiêu Coliforms. Đồng thời không phát hiện có sự lây nhiễm vi khuẩn Clostridium ở tất cả 116 mẫu được khảo sát. Bên cạnh đó, số lượng vi sinh vật có sự biến động theo mùa, nhiều nhất là mùa hè (tháng 4 và 5 ), tiếp theo là mùa xuân (tháng 2 và 3 ).

Tù khóa: Tổng số vi sinh vật hiếu khí, Coliforms, Clostridium, tổng nấm men nấm mốc, bún hến, cơm hến, vệ sinh an toàn thực phẩm.

\section{MỞ ĐẦU}

Thời gian gần đây, chất lượng vệ sinh an toàn thực phẩm luôn là vấn đề gây nhức nhối và nóng bỏng của xã hội, trong đó thức ăn đường phố là nguy cơ dẫn đến hàng loạt vụ ngộ độc thực phẩm. Dịch vụ kinh doanh thức ăn đường phố không chỉ ở Việt Nam mà tại nhiều nước trên thế giới cũng rất được ưa chuộng. Tuy nhiên, vấn đề đáng lo ngại là quản lý an toàn thực phẩm tại các cơ sở này không hề dễ dàng. Theo thống kê của Cục An toàn thực phẩm, năm 2016, trong số các vụ ngộ độc thực phẩm được ghi nhận trên toàn quốc thì 3,2 - 5,7\% tổng số vụ là do thức ăn đường phố, nhiều nơi xảy ra 2 - 3 vụ ngộ độc thực phẩm trên cùng một địa bàn. Phường An Cựu, thành phố Huế là một trong những địa điểm có dân cư đông, số lượng sinh viên cư trú nhiều, gần trục đường chính lượng xe qua lại lớn với nhiều cơ sở bán thức ăn đường phố. Bún hến, cơm hến là một trong những thức ăn đường phố phổ biến với người dân thành phố Huế. Vì vậy, khảo sát đánh giá mức độ nhiễm vi sinh vật gây bệnh trong bún hến, cơm hến là hết sức cần thiết.

\section{2. ĐỐI TƯợNG VÀ PHƯƠNG PHÁP NGHIÊN CÚU}

\section{1. Đối tượng nghiên cứu}

- Thực phẩm chế biến sẵn: bún hến, cơm hến.

- Nhóm vi sinh vật nghiên cứu: tổng vi sinh vật hiếu khí (VSVHK), Coliforms, Clostridium, tổng nấm men nấm mốc.

\subsection{Phương pháp nghiên cứu}

$$
\begin{aligned}
& \text { 2.2.1. Cõ̃ mẫu sản phẩm thực phẩm và chọn mẫu } \\
& \text { * Sử dụng công thức tính cỡ mẫu sau: } \quad n=\frac{z^{2} \cdot p(1-p)}{e^{2}}
\end{aligned}
$$


Trong đó:

- n: cỡ mẫu;

- z: độ tin cậy $(\mathrm{z}=1,96)$;

- p: tỷ lệ ước tính của tổng thể nhiễm vi sinh vật (theo một số nghiên cứu trước $=0,74)[6]$;

- e: là độ chính xác mong muốn $(\mathrm{e}=0,095)$.

* Chọn mẫu:

Tại mỗi địa điểm, chúng tôi thu thập ngẫu nhiên tất cả các loại sản phẩm thực phẩm cần nghiên cứu, bao gồm các loại bún hến, cơm hến. Với mỗi loại sản phẩm nếu đã được đóng gói sẵn, chọn ngẫu nhiên một trong số các sản phẩm đó. Nếu chưa được đóng gói sẵn, yêu cầu người bán hàng lấy một phần sản phẩm trong số đó.

Thời gian thu mẫu: mỗi tháng thu mẫu 3 lần (từ tháng 2 đến tháng 5 năm 2018) trên 2 đợt nghiên cứu: đợt 1 là tháng 2 và tháng 3 (nhiệt độ trung bình là: $22^{\circ} \mathrm{C}$ đến $27^{\circ} \mathrm{C}$ ) và đợt 2 là tháng 4 và tháng 5 (nhiệt độ trung bình là: $30^{\circ} \mathrm{C}$ đến $34^{\circ} \mathrm{C}$ ).

\subsubsection{Phương pháp nghiên cưu}

\subsubsection{Chuẩn bị mẫu}

Mẫu được trộn đều các thành phần, cân $250 \mathrm{~g}$ cho vào máy nghiền để đồng nhất. Sau đó cân $25 \mathrm{~g}$ mẫu hòa vào $225 \mathrm{ml}$ nước vô trùng có độ pha loãng 10-1, tiếp tục pha loãng theo dãy thập phân đến nồng độ mẫu thích hợp (“TCVN 6507 - 1/4: 2003”, 2003) [1].

\subsubsection{2. Định luợng vi sinh vật}

Định lượng tổng số vi sinh vật hiếu khí theo TCVN 4884:2005 [2];

Định lượng tổng số nấm men, nấm mốc theo TCVN 8275:2010 [5];

Định lượng Coliforms theo TCVN 6848:2007 [4];

Định lượng Clostridium theo TCVN 4991:2005 [3].

\subsubsection{Xủ lý số liệu}

Để so sánh giá trị trung bình số lượng vi sinh vật trong mẫu chúng tôi tiến hành chuyển số liệu giá trị thực nghiệm dưới dạng $\log 10 \mathrm{CFU} / \mathrm{g}$ để đảm bảo yêu cầu so sánh bằng phân tích phương sai và xử lý bằng phương pháp thống kê theo Excel 2007. Các thí nghiệm được lạ̣p lại 3 lần.

\section{Kết quả và thảo luận}

\subsection{Tổng vi sinh vật hiếu khí}

Kết quả phân tích định lượng tổng VSVHK trong mẫu cơm hến và bún hến ở phường An Cựu, thành phố Huế được thể hiện qua bảng 3.1.

Bảng 3.1. Số lựng mẫu nhiễm khuẩn về chỉ tiêu tổng VSVHK của mẫu bún hến và cơm hến tại phường An Cưu, thành phố Huế

\begin{tabular}{|c|c|c|c|c|c|c|}
\hline \multirow{2}{*}{ Đọt } & Loại mẫu & $\begin{array}{c}\text { Số mẫu } \\
\text { phân tích }\end{array}$ & $\begin{array}{c}\text { Số mẫu } \\
\text { nhiễm }\end{array}$ & Số mẫu KĐTC & $\begin{array}{c}\text { Tỉ lệ mẫu } \\
\text { K円TC (\%) }\end{array}$ & $\begin{array}{c}\text { Số lượng tế bào } \\
\text { (CFU/g) }\end{array}$ \\
\hline \multirow{3}{*}{1} & Bún hến & 20 & 20 & 17 & 85,0 & $<1-8,1 \times 10^{10}$ \\
\cline { 2 - 7 } & Cơm hến khô & 19 & 19 & 18 & 94,7 & $<1-7,5 \times 10^{11}$ \\
\cline { 2 - 7 } & Cơm hến nước & 19 & 19 & 17 & 89,5 & $<1-4,2 \times 10^{10}$ \\
\cline { 2 - 7 } & Tổng cộng & 58 & 58 & 52 & 89,7 & \\
\hline
\end{tabular}




\begin{tabular}{|c|c|c|c|c|c|c|}
\hline Đọt & Loại mẫu & $\begin{array}{c}\text { Số mẫu } \\
\text { phân tích }\end{array}$ & $\begin{array}{c}\text { Số mẫu } \\
\text { nhiễm }\end{array}$ & Số mẫu KÐTC & $\begin{array}{c}\text { Tỉ lệ mẫu } \\
\text { KĐTC (\%) }\end{array}$ & $\begin{array}{c}\text { Số lự̛ng tế bào } \\
(C F U / g)\end{array}$ \\
\hline \multirow{4}{*}{2} & Bün hến & 18 & 18 & 18 & 100,0 & $1,5 \times 10^{10}-6,7 \times 10^{10}$ \\
\hline & Cơm hến khô & 20 & 20 & 20 & 100,0 & $1,8 \times 10^{8}-3,0 \times 10^{11}$ \\
\hline & Cơm hến nước & 20 & 20 & 20 & 100,0 & $1,7 \times 10^{7}-3,0 \times 10^{11}$ \\
\hline & Tổng cộng & 58 & 58 & 58 & 100,0 & \\
\hline
\end{tabular}

Với 116 mẫu bún hến, cơm hến được phân tích đều có nhiễm VSVHK với số lượng dao động từ $<1 \mathrm{CFU} / \mathrm{g}$ đến 7,5x10 $0^{11} \mathrm{CFU} / \mathrm{g}$. Ở bảng 3.1, theo QĐ/46/2007 của Bộ Y tế (BYT) về giới hạn ô nhiễm tối đa cho phép đối với tổng VSVHK có trong thực phẩm cho thấy:

Đợt 1 (tháng 2 và tháng 3): có 17/20 mẫu bún hến không đạt tiêu chuẩn của Bộ Y tế (KĐTC BYT), chiếm 85,0\%, có 18/19 mẫu cơm hến khô không đáp ứng yêu cầu của Bộ Y tế, chiếm 94,8\% và có $17 / 19$ mẫu cơm hến nước không đáp ứng cầu của Bộ Y tế, chiếm 89,5\%.

Đợt 2 (tháng 4 và tháng 5): có 100,0\% mẫu bún hến, cơm hến khô cũng như cơm hến nước không đáp ứng yêu cầu của Bộ Y tế. Tỷ lệ này cao hơn so với khảo sát đợt 1 . Nguyên nhân có thể do nhiệt độ môi trường tăng cao hơn đợt 1 làm các vi sinh vật phát triển mạnh, thêm đó do chịu ảnh hưởng của khói bụi từ các công trình đang thi công nên làm tăng số lượng mẫu nhiễm khuẩn.

Theo Lương Đức Phẩm (2002), số lượng VSVHK càng nhiều cho thấy mức độ nhiê̂m bẩn của sản phẩm càng lớn, nguy cơ hư hỏng nhanh và có thể là nguy hiểm cho người tiêu dùng. Vì vậy trong thời điểm mùa hè, người tiêu dùng cần phải thận trọng hơn nữa khi lựa chọn sử dụng thực phẩm chế biến này [7].

\subsection{Tổng nấm men nấm mốc}

Tổng nấm men, nấm mốc trong mẫu cơm hến và bún hến ở phường An Cựu thành phố Huế được thể hiện qua bảng 3.2.

Bảng 3.2. Số lượng mẫu nhiếm khuẩn về chỉ tiêu tổng nấm men, nấm mốc của mẫu bưn hến và cơm hến tại phường An Cưuu, thành phố Huế

\begin{tabular}{|c|c|c|c|c|c|c|}
\hline Đọt & Lọ̣i mẫu & $\begin{array}{c}\text { Số mẫu } \\
\text { phân tích }\end{array}$ & $\begin{array}{c}\text { Số mẫu } \\
\text { nhiễm }\end{array}$ & $\begin{array}{c}\text { Số mẫu } \\
\text { KĐTC }\end{array}$ & $\begin{array}{c}\text { Tỉ lệ mấu } \\
\text { KĐTC (\%) }\end{array}$ & $\begin{array}{c}\text { Số lượng tế bào } \\
(C F U / g)\end{array}$ \\
\hline \multirow{4}{*}{1} & Bún hến & 20 & 20 & 17 & 85,00 & $<1-6,6 \times 10^{5}$ \\
\hline & Cơm hến khô & 19 & 19 & 15 & 79,00 & $<1-1,9 \times 10^{6}$ \\
\hline & Cơm hến nước & 19 & 19 & 17 & 89,50 & $<1-2,1 \times 10^{6}$ \\
\hline & Tổng cộng & 58 & 58 & 49 & 84,48 & \\
\hline \multirow{4}{*}{2} & Bún hến & 18 & 18 & 17 & 94,00 & $<1-2,2 \times 10^{6}$ \\
\hline & Cơm hến khô & 20 & 20 & 18 & 90,00 & $<1-0,2 \times 10^{6}$ \\
\hline & Cơm hến nước & 20 & 20 & 17 & 85,00 & $<1-2,1 \times 10^{6}$ \\
\hline & Tổng cộng & 58 & 58 & 52 & 89,65 & \\
\hline
\end{tabular}

Từ bảng 3.2, theo QĐ/46/2007 của Bộ Y tế về giới hạn ô nhiễm tối đa cho phép đối với tổng nấm men, nấm mốc có trong thực phẩm cho thấy: 
Ở đợt 1: có 17/20 mẫu bún hến không đáp ứng yêu cầu của Bộ Y tế, chiếm 85\%, có 15/19 mẫu cơm hến khô không đáp ứng yêu cầu của Bộ Y tế, chiếm 79\% và có 17/19 mẫu cơm hến nước không đáp ứng cầu của Bộ Y tế, chiếm 89,47\%.

Ở đợt 2: có 17/18 mẫu bún hến không đáp ứng yêu cầu của Bộ Y tế, chiếm 94\%, có 18/20 mẫu cơm hến khô không đáp ứng yêu cầu của Bộ Y tế, chiếm $90 \%$ và có $17 / 20$ mẫu cơm hến nước không đáp ứng yêu cầu của Bộ Y tế, chiếm $89,65 \%$. Hoàn toàn giống với mẫu nhiễm tổng VSVHK, tỷ lệ này cao hơn so với đợt 1 .

Đối với nấm mốc, khi nhiễm vào thực phẩm, gặp điều kiện thuận lợi như độ ẩm, nhiệt độ thích hợp sẽ phát triển và có thể sinh độc tố mycotoxin gây nguy hiểm cho sức khỏe người tiêu dùng (mặc dù không phải tất cả các loài nấm mốc đều sinh ra độc tố). Do đó việc phân tích chỉ tiêu này nhằm giúp người tiêu dùng quan tâm và thận trọng hơn khi lựa chọn thức ăn đường phố.

\subsection{Coliforms}

Kết quả phân tích định lượng Coliforms trong các mẫu cơm hến và bún hến ghi nhận biến động từ $1,5 \times 10^{3} \mathrm{MPN} / \mathrm{g}$ đến $1,5 \times 10^{7} \mathrm{MPN} / \mathrm{g}$.

Theo số liệu phân tích giá trị trung bình, nhóm bún hến có mức độ nhiễm cao nhất, thấp nhất là cơm hến nước.

Từ bảng 3.3, theo QĐ/46/2007 của Bộ Y tế về giới hạn ô nhiễm tối đa cho phép đối với chỉ tiêu Coliforms có trong thực phẩm cho thấy ở cả 2 đợt nghiên cứu không có mẫu bún hến và cơm hến đáp ứng yêu cầu của Bộ Y tế.

Bảng 3.3. Số lượng mẫu nhiễm khuẩn về chỉ tiêu Coliforms của mẫu bún hến và corm hến tại phường An Cưu, thành phố Huế

\begin{tabular}{|c|c|c|c|c|c|c|}
\hline Đọt & Lọ̣i mẫu & $\begin{array}{c}\text { Số mẫu } \\
\text { phân tích }\end{array}$ & $\begin{array}{c}\text { Số mẫu } \\
\text { nhiễm }\end{array}$ & $\begin{array}{c}\text { Số mẫu } \\
\text { KÐTC }\end{array}$ & $\begin{array}{c}\text { Tỉ lệ mẫu } \\
\text { KĐTC (\%) }\end{array}$ & $\begin{array}{c}\text { Số lự̆ng tế bào } \\
(M P N / g)\end{array}$ \\
\hline \multirow{4}{*}{1} & Bún hến & 20 & 20 & 20 & 100,0 & $4,5 \times 10^{3}-1,5 \times 10^{6}$ \\
\hline & Cơm hến khô & 19 & 19 & 19 & 100,0 & $1,2 \times 10^{4}-2,9 \times 10^{5}$ \\
\hline & Cơm hến nước & 19 & 19 & 19 & 100,0 & $1,5 \times 10^{3}-0,9 \times 10^{6}$ \\
\hline & Tổng cộng & 58 & 58 & 58 & 100,0 & \\
\hline \multirow{4}{*}{2} & Bún hến & 18 & 18 & 18 & 100,0 & $2,3 \times 10^{4}-1,5 \times 10^{7}$ \\
\hline & Corm hến khô & 20 & 20 & 20 & 100,0 & $0,9 \times 10^{4}-0,4 \times 10^{7}$ \\
\hline & Cơm hến nước & 20 & 20 & 20 & 100,0 & $9,0 \times 10^{4}-0,54 \times 10^{7}$ \\
\hline & Tổng cộng & 58 & 58 & 58 & 100,0 & \\
\hline
\end{tabular}

\subsection{Clostridium}

Kết quả phân tích các mẫu bún hến và cơm hến tại phường An Cựu, thành phố Huế trong cả 2 đợt đều không phát hiện có sự lây nhiễm Clostridium ở tất cả 116 mẫu được khảo sát. Đây là loài vi khuẩn nguy hiểm gây ngộ độc thực phẩm, tuy nhiên lại không phát hiện thấy chúng trong mẫu bún hến và cơm hến cho nên người tiêu dùng có thể phần nào yên tâm về chỉ tiêu này.

Để có bức tranh toàn cảnh về tình hình vệ sinh an toàn thực phẩm của các mẫu cơm hến và bún hến ở đường phố tại phường An Cựu, thành phố Huế qua hai đợt phân tích với 116 mẫu, số liệu tổng thể được trình bày qua hình 3.1 . 


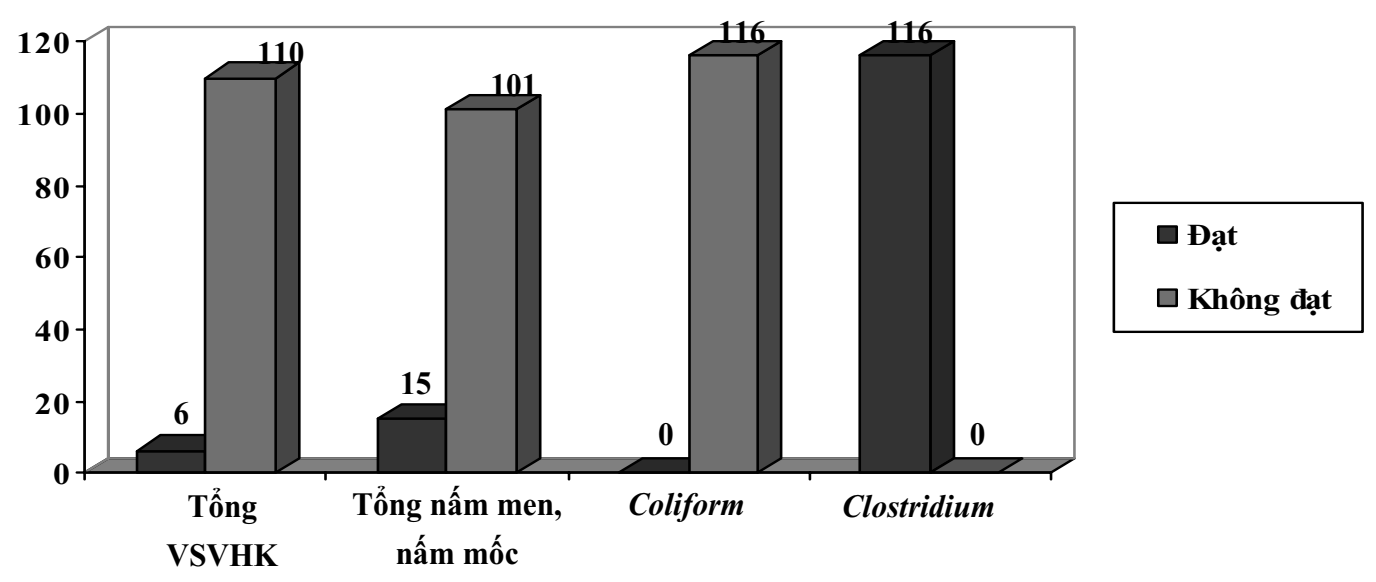

\section{KẾT LUẬN}

Hình 3.1. Tỷ lệ nhiễm vi sinh vật của các mẫu nghiên cưu

Qua kết quả nghiên cứu 116 mẫu cơm hến và bún hến tại phường An Cựu, thành phố Huế, chúng tôi rút ra một số kết luận sau:

- Đối với chỉ tiêu VSVHK có 6/116 mẫu đáp ứng yêu cầu của BYT, chiếm 5,2\%. Trong đó, bún hến có $2,6 \%$ mẫu đạt tiêu chuẩn cho phép, cơm hến khô có $0,9 \%$ mẫu đạt tiêu chuẩn cho phép, cơm hến nước có $1,7 \%$ mẫu đạt tiêu chuẩn cho phép.

- Đối với chỉ tiêu tổng nấm men, nấm mốc có $15 / 116$ mẫu đáp ứng yêu cầu của BYT, chiếm $12,9 \%$. Trong đó, bún hến có $3,4 \%$, cơm hến khô có $5,1 \%$, cơm hến nước có $4,3 \%$ mẫu đạt tiêu chuẩn cho phép. Bộ Y tế.

- Đối với chỉ tiêu Coliforms: trong 116 mẫu khảo sát không có mẫu nào đạt yêu cầu của

- Đối với chỉ tiêu Clostridium: không phát hiện có sự lây nhiễm vi khuẩn Clostridium ở tất cả 116 mẫu được khảo sát.

\section{KIẾN NGHI!}

- Tiếp tục phân tích các chỉ tiêu vi sinh vật trên với số lượng mẫu lớn hơn, trên nhiều loại thức ăn, mở rộng thêm các chỉ tiêu vi sinh vật khác.

- Các cơ quan chức năng nên tăng cường công tác giám sát, kiểm tra an toàn vệ sinh thực phẩm để tránh tình trạng buôn bán thực phẩm kém chất lượng, mất vệ sinh gây ảnh hưởng đến sức khỏe người dân.

\section{TÀI LIỆU THAM KHẢO}

1. Bộ Khoa học và Công nghệ (2003), TCVN 6507-1/4:2003 - Vi sinh vật trong thực phẩm và trong thức ăn chăn nuôi - Chuẩn bị mẫu thử huyền phù ban đầu và các dung dịch pha loãng thập phân để kiểm tra vi sinh vật.

2. Bộ Khoa học và Công nghệ (2005), TCVN 4884:2005 - Vi sinh vật trong thực phẩm và trong thức ăn chăn nuôi. Phương pháp định lượng vi sinh vật trên đĩa thạch - Kỹ thuật đếm khuẩn lạc ở $30^{\circ} \mathrm{C}$.

3. Bộ Khoa học và Công nghệ (2005), TCVN 4991:2005 - Vi sinh vật trong thực phẩm và trong thức ăn chăn nuôi. Phương pháp định lượng Clostridium perfringens trên đĩa thạch - Kỹ thuật đếm khuẩn lạc. 
4. Bộ Khoa học và Công nghệ (2007), TCVN 6848:2007 - Vi sinh vật trong thực phẩm và thức ăn chăn nuôi. Phương pháp định lượng Coliforms - Kỹ thuật đếm khuẩn lạc.

5. Bộ Khoa học và Công nghệ (2010), TCVN 8275:2010 - Vi sinh vật trong thực phẩm và trong thức ăn chăn nuôi. Phương pháp định lượng vi sinh vật trên đĩa thạch - Kỹ thuật đếm khuẩn lạc ở $30^{\circ} \mathrm{C}$.

6. Nguyễn Thành Huy (2004), "Nghiên cứu tình hình nhiễm vi khuẩn thức ăn chín ở một số quán cơm bình dân tại thành phố Huế”, Luận văn Thạc sĩ Y học, trường Đại học Y dược Huế.

7. Lương Đức Phẩm (2002), "Vi sinh vật học và ăn toàn vệ sinh thực phẩm”, NXB Nông nghiệp, Hà Nội.

\title{
Summary
}

\section{MICROORGANISMS CONTAMINATION IN STREET FOOD AT AN CUU WARD, HUE CITY}

\author{
Pham Thi Ngoc Lan ${ }^{1}$, Ngo Thi Bao Chau ${ }^{1}$, Tran Thi Hoang Oanh ${ }^{2}$ \\ ${ }^{I}$ College of Science, Hue University \\ ${ }^{2}$ Danang Biotechnology Center
}

One hundred and sixteen samples of mussel noodle and mussel rice were surveyed for microorganisms contamination at An Cuu ward, Hue city. The ratio of samples meeting the requirements of the total aerobic microorganisms in mussel rice, mussel rice with soup, mussel noodle samples was of $0.9 \%, 1.7 \%$ and $2.6 \%$, respectively. On the other hand, the proportion of samples meeting the requirements of total yeast and mold criteria in mussel rice, mussel rice with soup, and mussel noodle samples was of $5.1 \%, 4.3 \%$, and $3.4 \%$, respectively. Moreover, $100 \%$ samples failed to meet the requirements of the Ministry of Health regarding the Coliforms criteria, while Clostridium were not detected. Interestingly, seasonal fluctuation in microorganism contamination was observed. The contamination seems to be heavier in summer (April and May) than in spring (January and February).

Keywords: Total aerobic microorganisms, Coliforms, Clostridium, total yeast and mold, mussel noodle, mussel rice, food safety and hygiene. 